\title{
Clinical pretreatment risk factors and prediction of outcome using gallium 67 scintigraphy in patients with Hodgkin's lymphoma
}

\author{
IGNACIO GARCÍA ESCOBAR ${ }^{1}$, ANA LÓPEZ ${ }^{2}$, JUDIT RUBIO ${ }^{1}$, DAVID PÉREZ-CALLEJO ${ }^{1}$, \\ DOLORES CABALLERO BARRIGÓN ${ }^{3}$, PILAR TAMAYO ALONSO ${ }^{4}$, \\ ELENA ALMAGRO CASADO ${ }^{1}$ and MARIANO PROVENCIO PULLA ${ }^{1}$ \\ ${ }^{1}$ Department of Oncology, Puerta de Hierro University Hospital, 28222 Madrid; ${ }^{2}$ Department of Oncology, \\ University Hospital of León, 24071 León; Departments of ${ }^{3}$ Hematology and ${ }^{4}$ Nuclear Medicine, \\ University Hospital of Salamanca, 37007 Salamanca, Spain
}

Received March 16, 2015; Accepted July 16, 2015

DOI: $10.3892 / \mathrm{mco} .2015 .670$

\begin{abstract}
This study was conducted to investigate the prognostic effect and implications of gallium 67 scintigraphy (gallium scan) at mid-treatment and at the end of first-line treatment in patients with early- and advanced-stage Hodgkin's lymphoma (HL). A total of $216 \mathrm{HL}$ patients were included in the study. Gallium scan was performed at mid-treatment and at the end of first-line treatment. The overall survival (OS) and event-free survival (EFS) were calculated using the Kaplan-Meier method. The log-rank test was used to identify univariate predictors of EFS and OS. For early-stage disease, bulky mediastinal involvement (yes vs. no, 98 vs. $79 \%$, respectively; $\mathrm{P}=0.01$ ), erythrocyte sedimentation rate (good vs. adverse, 98 vs. $88 \%$, respectively; $\mathrm{P}=0.03$ ), presence of $\mathrm{B}$ symptoms (no vs. yes, 94 vs. $78 \%$, respectively; $\mathrm{P}=0.006$ ), post-chemotherapy disease status [complete response (CR) vs. unconfirmed CR (uCR) vs. partial response (PR) vs. progressive disease (PGR), 95 vs. 90 vs. 87 vs. $0 \%$, respectively; $\mathrm{P}<0.01]$ and gallium scan at mid-treatment and at the end of treatment (negative vs. positive, 88 vs. $20 \%, \mathrm{P}<0.001$; and 85 vs. $10 \%$, $\mathrm{P}<0.001$, respectively) significantly affected the EFS. In addition, age ( $<50$ vs. $\geq 50$ years, 96 vs. $78 \%$, respectively; $\mathrm{P}=0.01$ ), presence of $\mathrm{B}$ symptoms (no vs. yes, 97 vs. $87 \%$, respectively; $\mathrm{P}=0.03$ ), post-chemotherapy disease status (CR vs. uCR vs. PR vs. PGR, 95 vs. 90 vs. 90 vs. $0 \%$, respectively; $\mathrm{P}<0.01)$ and gallium scan results at mid-treatment and at the end of treatment (negative vs. positive, 87 vs. $60 \%$, $\mathrm{P}<0.001$; and 95 vs. $0 \%, \mathrm{P}<0.001$, respectively) significantly affected the OS. For advanced-stage disease, Hassenclever index (1-3 vs. $4-6,80$ vs. $57 \%$, respectively; $\mathrm{P}=0.05)$ and
\end{abstract}

Correspondence to: Dr Ignacio García Escobar, Department of Oncology, Puerta de Hierro University Hospital, 1 Manuel de Falla Street, 28222 Madrid, Spain

E-mail: naxto@hotmail.com

Key words: Hodgkin's lymphoma, gallium scan, prognostic factors, risk factors gallium scan results at mid-treatment and at the end of treatment (negative vs. positive, 84 vs. $18 \%, \mathrm{P}<0.001$; and 84 vs. $0 \%$, $\mathrm{P}<0.001$, respectively) significantly affected the EFS, whereas age at diagnosis ( $<50$ vs. $\geq 50$ years, 92 vs. $78 \%$, respectively; $\mathrm{P}=0.04)$, Hassenclever index (1-3 vs. $4-6,86$ vs. $61 \%$, respectively; $\mathrm{P}=0.04$ ) and gallium scan results at mid-treatment and at the end of treatment (negative vs. positive, 98 vs. $40 \%$, $\mathrm{P}<0.001$; and 97 vs. $23 \%, \mathrm{P}<0.001$, respectively) significantly affected the OS. On the multivariate analysis, gallium scan at the end of first-line treatment retained statistical significance in terms of EFS and OS. In conclusion, post-chemotherapy gallium scan is an important prognostic factor in patients with early- or advanced-stage HL and a predictor of adverse outcome.

\section{Introduction}

The majority of the patients diagnosed with Hodgkin's lymphoma (HL) may be succesfully treated with radiotherapy (RT) or conventional-dose chemotherapy, with $70 \%$ remaining alive at 10 years following diagnosis (1-3).

For patients with relapsed and refractory HL, second-line chemotherapy followed by autologous stem cell transplantation (ASCT) and a non-myeloablative conditioning regimen followed by allogeneic transplantation are currently considered to be viable therapeutic options (4).

Clinical risk factors are an expression of disease sensitivity and may indicate the patient's ability to respond to treatment. There is a considerable amount of retrospective information available in this respect for patients with HL (5-10) and the response of lymphoma to chemotherapy is considered by several authors as one of the most significant factors $(8,11,12)$. Functional imaging techniques, such as gallium $67\left({ }^{67} \mathrm{Ga}\right)$ scintigraphy (gallium scan) or positron emission tomography (PET) with 2-( $\left.{ }^{18} \mathrm{~F}\right)$-fluoro-2-deoxy-Dglucose, may be used to monitor the effect of treatment on lymphoma tissues (13-16).

Strong evidence has been accumulating, indicating that assessment of response after 1 or 2 cycles of chemotherapy, or after the end of first-line therapy, particularly with metabolic imaging methods such as gallium scan and, more recently, with 
PET, may identify patients with poor prognosis, for whom early treatment intensification may be considered (13-17). In this study, we present the results of a two-center retrospective study, in which we analyze the prognostic effect and implications of gallium scan at mid-treatment and at the end of first-line treatment in patients with early- and advanced-stage HL.

\section{Patients and methods}

Patient characteristics. This study included 216 HL patients who were treated between 1991 and 2004 at the University Hospital of Salamanca (Salamanca, Spain) and the Puerta de Hierro University Hospital (Madrid, Spain). The local Ethics Committees of the participating centers approved the study protocol, taking into consideration the existing regulations at that time. The patient characteristics are summarized in Table I. The patients included 117 (54.2\%) men and 99 (45.8\%) women, with a median age of 37 years (range, 11-80 years). All the patients had histological evidence of HL confirmed by hematopathologists at the treating hospital; 148 patients $(68.5 \%)$ had nodular sclerosis, 53 (24.5\%) mixed-cellularity and 7 (3.3\%) lymphocyte-predominant types. A total of 79 patients $(36.6 \%)$ presented with B sympthoms at diagnosis and 144 (67.0\%) were diagnosed with stage I or II disease. As regards the extension of the lymphoma, $69.0 \%$ of the patients did not exhibit bulky disease, whereas only 35 patients (16.0\%) exhibited extranodal disease.

Treatment. The treatment details are described in Table II. Considering the 144 patients with early-stage disease who completed the induction therapy, $27(18.7 \%)$ received RT alone, $82(57.0 \%) 3$ cycles of doxorubicin, bleomycin, vinblastine and dacarbazine (ABVD) followed by RT and 35 (24.3\%) received mechlorethamine, vincristine, procarbazine and prednisone (MOPP) followed by RT. Among the 72 advanced-stage patients, $58(80.6 \%)$ received $3-8$ cycles of ABVD and $13(18.0 \%)$ 6-8 cycles of MOPP and components of the ABVD regimen without dacarbazine (MOPP/ABV regimen). One patient received methotrexate, doxorubicin, cyclophosphamide, vincristine, prednisone and bleomycin (MACOP-B regimen). Finally, 55 patients $(76.4 \%)$ received consolidation treatment with RT following chemotherapy.

Restaging gallium. Patients were considered eligible for the study when they had a ${ }^{67} \mathrm{Ga}$-avid lymphoma established by a baseline gallium scan prior to treatment and a gallium scan for restaging performed midway through chemotherapy (114 patients, $52.7 \%$ ) and/or at the end of the first-line treatment (204 patients, 94.4\%). This cohort of patients were treated before PET was available at our institution; therefore, none of the patients underwent PET. Four patients $(1.8 \%)$ underwent mid-chemotherapy gallium scan alone, 94 patients (43.5\%) underwent end-first-line treatment gallium scan alone and 110 patients $(51.0 \%)$ underwent both examinations. Apart from one, all patients with a positive restaging gallium scan at the end of treatment received additional chemotherapy or underwent high-dose therapy with stem-cell rescue.

Clinical response following chemotherapy. Clinical response following treatment was determined based on the computed
Table I. Clinical characteristics at diagnosis.

\begin{tabular}{lr} 
Characteristics & $\begin{array}{r}\text { Patient no. }(\%) \\
(\mathrm{n}=216)\end{array}$ \\
\hline Age, years & \\
Median (range) & $37(11-80)$ \\
Gender & \\
Male & $117(54.2)$ \\
Female & $99(45.8)$ \\
Histological type & \\
Nodular sclerosis & $148(68.5)$ \\
Mixed-cellularity & $53(24.5)$ \\
Lymphocyte-predominant & $7(3.3)$ \\
Other & $8(3.7)$ \\
ECOG PS & $180(84.0)$ \\
0, 1 & $36(16.0)$ \\
2-5 & \\
B symptoms & $79(36.6)$ \\
No & $137(63.4)$ \\
Yes & \\
Ann Arbor stage & $149(67.0)$ \\
I-II & \\
III-IV & \\
Bulky disease & \\
No & \\
Yes & \\
&
\end{tabular}

Bone marrow involvement

No

Yes

Extranodal disease

No

Yes

Positive CT at diagnosis

$216(100.0)$

Positive ${ }^{67} \mathrm{Ga}$ scan at diagnosis

$216(100.0)$

${ }^{67} \mathrm{Ga}$, gallium 67; ECOG PS, Eastern Cooperative Oncology Group performance status; CT, computed tomography.

tomography (CT) scan or physical examination findings at the end of chemotherapy or RT, using the guidelines developed by the International Workshop on Response Criteria for non-HL (18). A complete response (CR) was defined as negative physical examination and residual disease of $\leq 1 \mathrm{~cm}$; an unconfirmed CR (uCR) was defined as $>75 \%$ reduction in tumor volume, with residual disease of $\leq 2 \mathrm{~cm}$; a partial response (PR) was defined as $>50 \%$ reduction in tumor volume; stable disease was defined as $<50 \%$ reduction in tumor volume; and progressive disease was defined as an increase in the size of initial disease or development of new foci. Relapsed disease was defined as further disease progression or appearance of new disease foci after a response had been achieved with the initial course of treatment. 
${ }^{67} \mathrm{Ga}$ imaging. For gallium scan studies, the patients received 7-10 mCi (259-370 MBq) intravenous injection of ${ }^{67} \mathrm{Ga}$ citrate and imaging was performed at $72 \mathrm{~h}$. Whole-body anterior and posterior planar images were acquired with a dual-head camera attached to a medium-energy collimator and 3 energy peaks of 93, 184 and $296 \mathrm{keV}$ (20\% window), using a 256x768 matrix and a scanning speed to achieve an information density of $>1,500,000$ counts for each view. In addition, single-photon emission CT (SPECT) of the chest, abdomen and pelvis was performed with the same camera at $3^{\circ}$ intervals and $25 \mathrm{sec} /$ stop using $64 \times 64$ matrix. Reconstruction of the SPECT data was performed using a low pass pre-filter (order 5.0, cut-off 0.31) and transverse reconstruction with a ramp filter. Attenuation correction was not applied and the files were reconstructed in transverse, sagittal and coronal planes. Additional delayed images were obtained in selected patients in whom the SPECT images failed to differentiate between normal and abnormal bowel activity. Nuclear medicine physicians did not have access to the CT images or results when evaluating the gallium scans. The gallium scan was considered positive for the presence of disease when abnormal focal or diffuse uptake of ${ }^{67} \mathrm{Ga}$ was observed in a localization incompatible with normal structures and unexplained by other causes. Diffuse lung uptake (19) and bilateral perihilar uptake (20) were not considered to indicate the presence of lymphoma.

Statistical analysis. In order to identify the factors that affected outcome, the following clinical and biological characteristics were evaluated in univariate and multivariate analyses: Gender, age, Eastern Cooperative Oncology Group performance status, Ann Arbor stage, size of tumor, bulky disease, presence of B symptoms, bone marrow involvement, number of extranodal sites, erythrocyte sedimentation rate (ESR), lactate dehydrogenase, $\beta 2$-microglobulin, copper and ceruloplasmin levels, number of leukocytes and lymphocytes and hemoglobin levels. Finally, CT and gallium scan results after 3 cycles of treatment and at the end of induction therapy were included.

Comparison of response rates was performed using the $\chi^{2}$ test. The patients were analyzed with respect to event-free survival (EFS) and overall survival (OS). OS was calculated from the day of diagnosis to the day of death or last follow-up. EFS was calculated from the day of diagnosis to the day of treatment failure (relapse, progression or no response to induction therapy). Probabilities were estimated using the Kaplan-Meier method. Differences between groups according to the different covariates were analyzed by the log-rank test. A forward stepwise Cox proportional hazards regression model was used for multivariate analysis. All the P-values reported were two-sided and $\mathrm{P}<0.05$ was considered to indicate statistically significant differences.

\section{Results}

Follow-up and survival. The median follow-up time for the 216 patients was 107 months. The 5-year Kaplan-Meier OS and EFS estimates were 91 and $82 \%$, respectively. The corresponding OS and EFS estimates for the 144 patients with stage I-II disease at diagnosis were 92 and $87 \%$, respectively,
Table II. Induction treatment.

First-line treatment

Patient no. (\%)

Early stage $(n=144)$

RT alone

ABVD $\times 2 / 3+R T$

$82(57.0)$

MOPP x $2 / 3+\mathrm{RT}$

$35(24.3)$

Advanced stage $(n=72)$

$\begin{array}{lc}\text { ABVD x 6/8 } & 58(80.6) \\ \text { MOPP-ABV x 6/8 } & 13(18.0) \\ \text { MACOP-B } & 1(1.4) \\ \text { RT bulky } & 55(76.4)\end{array}$

RT, radiotherapy; ABVD, doxorubicin, bleomycin, vinblastine and dacarbazine; MOPP, mechlorethamine, vincristine, procarbazine and prednisone; MACOP-B, methotrexate, doxorubicin, cyclophosphamide, vincristine, prednisone and bleomycin.

whereas the corresponding OS and EFS for the 72 patients with stage III-IV disease were 86 and $77 \%$, respectively.

Restaging gallium scan and clinical response following chemotherapy. The results of restaging gallium scanning are presented in Table III. Among the 114 patients who underwent a mid-chemotherapy gallium scan, $12(10.5 \%)$ had a positive result. For the 204 patients who underwent a post-chemotherapy gallium scan, the results were positive in 10 (4.9\%). Among the 110 patients who underwent both a mid- and a post-chemotherapy gallium scan, 5 patients $(4.6 \%)$ had a positive scan midway through treatment and became negative after treatment; 2 patients $(1.8 \%)$ had a negative gallium scan at mid-chemotherapy and became positive at the end of chemotherapy; and in 5 patients (4.6\%), the results were positive in both mid- and post-chemotherapy gallium scans. The remaining 98 patients $(89 \%)$, had negative results at both time points.

Based on the CT scan or physical examination findings, 206 patients (94\%) achieved complete or uCR after first-line treatment, 4 patients (2\%) had PR and 6 patients $(4 \%)$ had progressive disease,without any patient achieving stable disease. All 10 patients with a positive gallium scan at the end of first-line treatment had progressive disease, $80 \%$ of whom succumbed due to disease progression and $20 \%$ were rescued with treatment. Of the 194 patients with negative gallium scan at the end of treatment, $23(11.8 \%)$ suffered an event, whereas 141 of them exhibited CR (72.6\%) and $53 \mathrm{uCR}(27.3 \%)$.

Treatment outcome in patients with a positive restaging gallium scan. Of the 216 patients included in the series, 16 presented a positive gallium scan result and treatment was changed in $4(25 \%)$ patients after 2 cycles of chemotherapy. The 4 patients were rescued with chemotherapy and ASCT. Another 3 patients (18.7\%) continued with the first-line treatment despite the gallium scan findings at mid-treatment, with repeat positive results at the end of first-line treatment, and received rescue chemotherapy followed by TASPE. Of 
Table III. Restaging gallium scan and clinical response following chemotherapy.

A, Gallium scan

\begin{tabular}{lcc}
\hline Time point & Positive $(\%)$ & Negative $(\%)$ \\
\hline Mid-treatment $(\mathrm{n}=114)$ & $12(10.5)$ & $102(89.5)$ \\
End of treatment $(\mathrm{n}=204)$ & $10(4.9)$ & Negative to positive, 2(1.8) \\
Mid-end treament $(\mathrm{n}=110)^{\mathrm{a}}$ & Positive to negative, 5 (4.6) & Negative-negative, 98 (89.0) \\
\hline
\end{tabular}

$\mathrm{B}$, Clinical response to treatment ${ }^{\mathrm{b}}$

Type of response

No. $(\%)$

$\mathrm{CR} / \mathrm{uCR}$

$206(94.0)$

PR

PGR

$6(4.0)$

${ }^{a}$ Conversion of gallium scan results during treatment: From positive at mid-treatment to negative at the end of first-line treatment; from negative to positive result after induction treatment; and those who maintained the same gallium scan results during the entire duration of the induction treatment. ${ }^{b}$ Clinical response based on computed tomograhy scan results and clinical examination findings. CR, complete response; uCR, unconfirmed CR; PR, partial response; PGR, progressive disease.

these 7 patients, 3 remained alive and disease-free at the last follow-up ( 2 of whom had positive gallium scan results at the end of first-line treatment). The remaining 4 patients succumbed to progressive lymphoma. Of the 9 patients with positive gallium scans and without change of treatment, 6 patients succumbed, 2 of whom due to secondary neoplasms. Of the remaining 3 cases, 1 should be considered a false-positive result secondary to $\mathrm{RT}$, the second patient suffered a late relapse and remained lymphoma-free following conventional rescue treatment plus consolidation with RT, whereas the third patient became negative (after a mid-treatment positive result) following 4 more chemotherapy cycles and consolidation RT of bulky mediastinal disease, and remained disease-free at the last follow-up.

Univariate analysis of stage I-II patients. The significant variables in the univariate analysis are listed in Table IV. For stages I-II, the analysis was restricted to 144 patients. The variables included in the analysis were gender, age at diagnosis, bulky mediastinal involvement, B symptoms, ESR, post-chemotherapy status, and gallium scan at mid-treatment and at the end of first-line treatment.

The factors found to significantly affect the EFS were bulky mediastinal involvement (yes vs. no, 98 vs. $79 \%$, respectively; $\mathrm{P}=0.01)$, ESR [good vs. adverse ( $>50$ without or $>30$ with $\mathrm{B}$ symptoms), 98 vs. $88 \%$, respectively; $\mathrm{P}=0.03$ ], presence of $\mathrm{B}$ symptoms (no vs. yes, 94 vs. $78 \%$, respectively; $\mathrm{P}=0.006$ ), post-chemotherapy disease status (CR vs. uCR vs. PR vs. PGR, 95 vs. 90 vs. 87 vs. 0\%, respectively; $\mathrm{P}<0.01)$ and gallium scan results at mid-treatment and at the end of treatment (negative vs. positive, 88 vs. $20 \%, \mathrm{P}<0.001$; and 85 vs. $10 \%, \mathrm{P}<0.001$, respectively). As regards OS, the factors with statistical significance included age ( $<50$ vs. $\geq 50$ years, 96 vs. $78 \%$, respectively; $\mathrm{P}=0.01$ ), presence of B symptoms (no vs. yes, 97 vs. $87 \%$, respectively; $\mathrm{P}=0.03$ ), post-chemotherapy disease status (CR vs. uCR vs. PR vs. PGR, 95 vs. 90 vs. 90 vs. $0 \%$, respectively; $\mathrm{P}<0.01$ ) and gallium scan results at mid-treatment and at the end of treatment (negative vs. positive, 87 vs. $60 \%$, $\mathrm{P}<0.001$; and 95 vs. $0 \%, \mathrm{P}<0.001$, respectively).

Univariate analysis of stage III-IV patients. For stage III-IV disease, the analysis was restricted to 72 patients and the results are listed in Table IV. The variables included in the analysis were gender, age at diagnosis, Hassenclever index classified into two groups according to risk (1-3 vs. 4-6), and gallium scan at mid-treatment and at the end of first-line treatment.

The factors found to significantly affect the EFS were Hassenclever index (1-3 vs. 4-6, 80 vs. 57\%, respectively; $\mathrm{P}=0.05)$ and gallium scan results at mid-treatment and at the end of treatment (negative vs. positive, 84 vs. $18 \%$, $\mathrm{P}<0.001$; and 84 vs. $0 \%, \mathrm{P}<0.001$, respectively). Age at diagnosis (<50 vs. $\geq 50$ years, 92 vs. $78 \%$, respectively; $\mathrm{P}=0.04$ ), Hassenclever index (1-3 vs. 4-6, 86 vs. $61 \%$, respectively; $\mathrm{P}=0.04$ ) and gallium scan results at mid-treatment and at the end of treatment (negative vs. positive, 98 vs. $40 \%, \mathrm{P}<0.001$; and 97 vs. $23 \%, \mathrm{P}<0.001$, respectively) were the factors significantly affecting $\mathrm{OS}$.

Multivariate analysis. Considering patients with stage I-II disease, only gallium scan results at the end of first-line treatment retained statistical significance in the Cox regression model $[\mathrm{P}<0.001$, hazard ratio $(\mathrm{HR})=2.1$ and 95\% confidence interval (CI): $1.91-7.9$ for EFS; and $\mathrm{P}=0.03$, $\mathrm{HR}=1.9$ and $95 \% \mathrm{CI}$ : 1.08-5.8 for OS]. Similarly, when considering stage III-IV patients, gallium scan at the end of treatment retained statistical significance $(\mathrm{P}=0.028, \mathrm{HR}=3$ and 95\% CI: $1.07-3.4$ for $\mathrm{EFS}$; and $\mathrm{P}=0.003, \mathrm{HR}=4$ and 95\% CI: 1.45-6.07 for OS) (data not shown). 
Table IV. Univariate analysis of prognostic factors.

\begin{tabular}{|c|c|c|c|c|c|}
\hline Prognostic factors & Patient no. & $\begin{array}{c}\text { Cumulative } \\
\text { EFS }(\%)\end{array}$ & P-value & $\begin{array}{c}\text { Cumulative } \\
\text { OS }(\%)\end{array}$ & P-value \\
\hline \multicolumn{6}{|l|}{ Stages I-II $(n=144)$} \\
\hline Post-chemotherapy status & & & $<0.001$ & & $<0.001$ \\
\hline Complete response & 117 & 95 & & 95 & \\
\hline Unconfirmed complete response & 20 & 90 & & 90 & \\
\hline Partial response & 4 & 87 & & 90 & \\
\hline Progressive disease & 3 & 0 & & 0 & \\
\hline Age at diagnosis, years & & & 0.9 & & 0.01 \\
\hline$<50$ & 128 & 86 & & 96 & \\
\hline$\geq 50$ & 16 & 88 & & 78 & \\
\hline Gender & & & 0.9 & & 0.9 \\
\hline Male & 71 & 86 & & 92 & \\
\hline Female & 73 & 85 & & 94 & \\
\hline Bulky involvement & & & 0.01 & & 0.07 \\
\hline Yes & 52 & 98 & & 90 & \\
\hline No & 92 & 79 & & 93 & \\
\hline B symptoms & & & 0.006 & & 0.03 \\
\hline Yes & 49 & 78 & & 87 & \\
\hline No & 95 & 94 & & 97 & \\
\hline Erythrocyte sedimentation rate & & & 0.03 & & 0.6 \\
\hline Good & 84 & 98 & & 94 & \\
\hline Adverse $^{a}$ & 60 & 88 & & 92 & \\
\hline Mid-treatment gallium scan & & & $<0.001$ & & $<0.001$ \\
\hline Negative & 67 & 88 & & 87 & \\
\hline Positive & 5 & 20 & & 60 & \\
\hline End-treatment gallium scan & & & $<0.001$ & & $<0.001$ \\
\hline Negative & 136 & 85 & & 95 & \\
\hline Positive & 2 & 10 & & 0 & \\
\hline \multicolumn{6}{|l|}{ Stages III-IV (n=72) } \\
\hline Gender & & & 0.3 & & 0.07 \\
\hline Male & 46 & 79 & & 82 & \\
\hline Female & 26 & 75 & & 80 & \\
\hline Age at diagnosis, years & & & 0.4 & & 0.04 \\
\hline$<50$ & 52 & 82 & & 92 & \\
\hline$\geq 50$ & 20 & 76 & & 78 & \\
\hline Hassenclever index ${ }^{\mathrm{b}}$ & & & 0.05 & & 0.04 \\
\hline $1-3$ & 57 & 80 & & 86 & \\
\hline $4-6$ & 15 & 57 & & 61 & \\
\hline Mid-treatment gallium scan & & & $<0.001$ & & $<0.001$ \\
\hline Negative & 35 & 84 & & 98 & \\
\hline Positive & 7 & 18 & & 40 & \\
\hline End-treatment gallium scan & & & $<0.001$ & & $<0.001$ \\
\hline Negative & 59 & 84 & & 97 & \\
\hline Positive & 7 & 0 & & 23 & \\
\hline
\end{tabular}

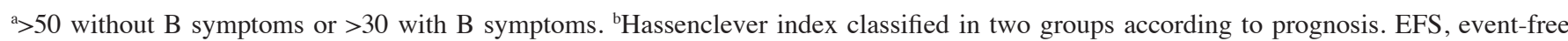
survival; OS, overall survival; P-values in bold print denote statistically significant differences.

Survival analysis. A total of 22 patients had succumbed to the disease at the time of the analysis. Of these, 9 patients succumbed to progressive HL, 7 secondary to infectious complications (3 of whom were under treatment with high-dose chemotherapy and stem cell transplantation), and 1 patient secondary to the bleomycin pulmonary toxicity. The 
remaining 5 patients developed secondary neoplasms $(4$ solid tumors and 1 myelodysplastic syndrome with a high-grade International Prognostic Scoring System score).

\section{Discussion}

This study reports the results of gallium scan and other prognostic factors in 216 patients with stage I-IV Hodgkin's disease following first-line treatment with chemotherapy and/or RT. Long-term treatment efficacy and predictors of relapse were included in the analysis. The 91 and $82 \%$ 5-year OS and EFS were in concordance with previous reports (21-23). A variety of patient, disease and laboratory factors have been shown to affect the outcome of HL patients. For patients with early-stage disease, age, extranodal involvment, bulky disease and ESR among others have been associated with long-term prognosis (24-26); for advance-stage cases, Hassenclever index has been found to be the most significant predictor of outcome (26-29).

A number of these prognostic indicators lost their prognostic significance in the context of combined modality therapy with higher disease control rates. CT has been considered the gold standard for restaging patients with lymphoma (30). Considering the common finding of persistent masses on CT scan, the assessment of response and, consequently, the disease status, often represent a problem among patients diagnosed with HL due to the difficulties in distinguishing fibrotic tissue from active disease (31). In addition to PET scan, which is a technique based on tumor metabolic rate to distinguish fibrotic tissue from residual masses $(32,33)$, gallium scan has been successfully used for several years for this purpose in patients with HL following standard chemotherapy and prior to autologous hematopoietic transplantation $(34,35)$.

In the present study, the most important predictor for EFS and OS was gallium scan results during and after chemotherapy. Considering a global analysis of prognostic factors, only gallium scan at the end of the first-line treatment retained statistical significance in the multivariate analysis. Other authors have reported similar results in this respect (36-38), although there is significant heterogeneity in the series and the majority refer to high-grade lymphomas, particularly non-HL. $\mathrm{Ng}$ et al (39) reported similar results in HL series with the limitation of the univariate analysis to early stages, including patients treated with ABVD alone and with a high proportion of RT-treated patients. Our series analyzed both groups and several described prognostic factors for early and advanced stages; according with our results, gallium scan at the end of treatment should be considered to be the strongest prognostic factor.

Considering the presence of residual gallium scan avidity as an adverse predictor of outcome, the optimal therapeutic approach for this group of patients who do not achieve CR at mid-treatment or at the end of first-line treatment has not yet been clearly determined.

In conclusion, the results of the present study confirm the significance of functional imaging techniques in the prognostic evalution of patients with HL. Post-chemotherapy restaging gallium scan results were highly predictive of treatment outcome, with more statistically significant implications compared with other classic established prognostic factors in patients with early- or advanced-stage disease. Considering patients with positive results at mid- or end-treatment, high-dose therapy with stem cell rescue is a viable rescue therapy option for refractory patients, although not necessarily for all patients, considering the clinical and biological characteristics of this type of lymphoma; each case should be considered individually, taking into consideration disease response, extension and biological activity. However, futher studies are required to obtain more solid conclusions. In the PET era, gallium scan remains a viable option for the accurate prognostic characterization of this group of patients.

\section{References}

1. Sureda A, Arranz R, Iriondo A, Carreras E, Lahuerta JJ, García-Conde J, Jarque I, Caballero MD, Ferrà C, López A, et al; Grupo Español de Linformas/Transplante Autólogo de Médula Osea Spanish Cooperative Group: Autologous stem-cell transplantation for Hodgkin's disease: Results and prognostic factors in 494 patients from the Grupo Español de Linfomas/Transplante Autólogo de Médula Osea Spanish Cooperative Group. J Clin Oncol 19: 1395-1404, 2001

2. Longo DL, Young RC, Wesley M, Hubbard SM, Duffey PL, Jaffe ES and DeVita VT Jr: Twenty years of MOPP therapy for Hodgkin's disease. J Clin Oncol 4: 1295-1306, 1986.

3. Prosnitz LR, Farber LR, Kapp DS, Scott J, Bertino JR, Fischer JJ and Cadman EC: Combined modality therapy for advanced Hodgkin's disease: 15-year follow-up data. J Clin Oncol 6: 603-612, 1988.

4. Reece DE, Barnett MJ, Connors JM, Fairey RN, Fay JW, Greer JP, Herzig GP, Herzig RH, Klingemann HG, LeMaistre CF, et al: Intensive chemotherapy with cyclophosphamide, carmustine, and etoposide followed by autologous bone marrow transplantation for relapsed Hodgkin's disease. J Clin Oncol 9: 1871-1879, 1991.

5. Abrahamsen AF, Hannisdal E, Nome O, Holte H, Hager B, Langholm R and Kvaløy S: Clinical stage I and II Hodgkin's disease: Long-term results of therapy without laparotomy. Experience at one institution. Ann Oncol 7: 145-150, 1996.

6. Hughes-Davies L, Tarbell NJ, Coleman CN, Silver B, Shulman LN, Linggood R, Canellos GP and Mauch PM: Stage IA-IIB Hodgkin's disease: Management and outcome of extensive thoracic involvement. Int J Radiat Oncol Biol Phys 39: 361-369, 1997.

7. Vlachaki MT, Hagemeister FB, Fuller LM, Besa PC, Hess MA, Brown B, Cabanillas F and Cox JD: Long-term outcome of treatment for Ann Arbor Stage I Hodgkin's disease: Prognostic factors for survival and freedom from progression. Int J Radiat Oncol Biol Phys 38: 593-599, 1997.

8. Smolewski P, Robak T, Krykowski E, Blasiñska-Morawiec M, Niewiadomska H, Pluzanska A, Chmielowska E and Zambrano O: Prognostic factors in Hodgkin's disease: Multivariate analysis of 327 patients from a single institution. Clin Cancer Res 6: 1150-1160, 2000.

9. Amini RM, Enblad G, Gustavsson A, Ekman T, Erlanson M, Haapaniemi E and Glimelius B: Treatment outcome in patients younger than 60 years with advanced stages (IIB-IV) of Hodgkin's disease: The Swedish National Health Care Programme experience. Eur J Haematol 65: 379-389, 2000.

10. Zapatero A, López MA, Cerezo L, De Vidales CM, MarIn A and Pérez-Torrubia A: Stage I-III Hodgkin's disease: Outcome and pattern of failure following treatment with radiation therapy and chemotherapy in a modern era. Hematology 7: 43-50, 2002.

11. Bonfante V, Santoro A, Viviani S, Devizzi L, Balzarotti M, Soncini F, Zanini M, Valagussa P and Bonadonna G: Outcome of patients with Hodgkin's disease failing after primary MOPP-ABVD. J Clin Oncol 15: 528-534, 1997.

12. Bessell EM, Bouliotis G, Armstrong S, Baddeley J, Haynes AP, O'Connor S, Nicholls-Elliott $\mathrm{H}$ and Bradley M: Long-term survival after treatment for Hodgkin's disease (1973-2002): Improved survival with successive 10-year cohorts. Br J Cancer 107: 531-536, 2012.

13. Front D, Bar-Shalom R, Mor M, Haim N, Epelbaum R, Frenkel A, Gaitini D, Kolodny GM and Israel O: Hodgkin disease: Prediction of outcome with ${ }^{67} \mathrm{Ga}$ scintigraphy after one cycle of chemotherapy. Radiology 210: 487-491, 1999. 
14. Cooper DL, Neumann RD and Caride VJ: A critical assessment of the prognostic value of gallium-67 scintigraphy in lymphoma In: Nuclear Medicine Annual. Freeman L (ed). Lippincott Williams and Wilkins, Philadelphia, PA, pp211-232, 2000.

15. Delbeke D: Oncological applications of FDG PET imaging: Brain tumors, colorectal cancer, lymphoma and melanoma. J Nucl Med 40: 591-603, 1999.

16. Kobe C, Kuhnert G, Kahraman D, Haverkamp H, Eich HT, Franke M, Persigehl T, Klutmann S, Amthauer H, Bockisch A, et al: Assessment of tumor size reduction improves outcome prediction of positron emission tomography/computed tomography after chemotherapy in advanced-stage Hodgkin lymphoma. J Clin Oncol 32: 1776-1781, 2014.

17. Iltis A, Eder V, Blasco H, Colombat P and Sénécal D: Decisional Early Interim ${ }^{18} \mathrm{~F}$-fluoro-2-deoxy-D-glucose positron emission tomography after two cycles of chemotherapy in de novo Hodgkin lymphoma. Acta Haematol 133: 172-178, 2015.

18. Cheson BD, Horning SJ, Coiffier B, Shipp MA, Fisher RI, Connors JM, Lister TA, Vose J, Grillo-López A, Hagenbeek A, et al NCI Sponsored International Working Group: Report of an international workshop to standardize response criteria for non-Hodgkin's lymphomas (Review). J Clin Oncol 17: 1244, 1999.

19. Bar-Shalom R, Israel O, Haim N, Leviov M, Epelbaum R, Frenkel A, Ben-Haim S, Kolodny GM and Front D: Diffuse lung uptake of Ga-67 after treatment of lymphoma: Is it of clinical importance? Radiology 199: 473-476, 1996.

20. Even-Sapir E, Bar-Shalom R, Israel O, Frenkel A, Iosilevsky G, Haim N, Epelbaum R, Gaitini D, Kolodny GM and Front D: Single-photon emission computed tomography quantitation of gallium citrate uptake for the differentiation of lymphoma from benign hilar uptake. J Clin Oncol 13: 942-946, 1995.

21. Eghbali H, Bonichon F, David B, Rojouan J, Audebert AA, Blanc CM, Zittoun R, Hoerni B and Najman A; Pierre and Marie Curie Group (GPMC): Combination of ABVD and radiotherapy in early stages of Hodgkin's disease: Analysis of a series of 94 patients. Radiother Oncol 18: 127-136, 1990.

22. André M, Brice P, Cazals D, Hennequin C, Fermé C, Kerneis Y, Rousselot P, Zini JM, Lepage E and Gisselbrecht C: Results of three courses of adriamycin, bleomycin, vindesine, and dacarbazine with subtotal nodal irradiation in 189 patients with nodal Hodgkin's disease (stage I, II and IIIA). Hematol Cell Ther 39: 59-65, 1997.

23. Brusamolino E, Lunghi F, Orlandi E, Astori C, Passamonti F Baraté C, Pagnucco G, Baio A, Franchini P, Lazzarino M, et al: Treatment of early-stage Hodgkin's disease with four cycles of ABVD followed by adjuvant radio-therapy: Analysis of efficacy and long-term toxicity. Haematologica 85: 1032-1039, 2000

24. Specht L, Nordentoft AM, Cold S, Clausen NT and Nissen NI Tumor burden as the most important prognostic factor in early stage Hodgkin's disease. Relations to other prognostic factors and implications for choice of treatment. Cancer 61: 1719-1727, 1988.

25. Bonfante V, Santoro A, Viviani S, Zucali R, Devizzi L, Zanini M, Tesoro Tess JD, Valagussa P, Banfi A and Bonadonna G: Early stage Hodgkin's disease: Ten-year results of a non-randomised study with radiotherapy alone or combined with MOPP. Eur J Cancer 29A: 24-29, 1992.

26. Ansell SM: Hodgkin lymphoma: 2014 update on diagnosis, risk-stratification and management. Am J Hematol 89: 771-779, 2014.
27. Ranson MR, Radford JA, Swindell R, Deakin DP, Wilkinson PM, Harris M, Johnson RJ and Crowther D: An analysis of prognostic factors in stage III and IV Hodgkin's disease treated at a single centre with MVPP. Ann Oncol 2: 423-429, 1991

28. Fermé C, Bastion Y, Brice P, Lederlin P, Diviné M, Gabarre J, Assouline D, Ferrant A, Berger F and Lepage E: Prognosis of patients with advanced Hodgkin's disease: Evaluation of four prognostic models using 344 patients included in the Group d'Etudes des Lymphomes de l'Adulte Study. Cancer 80: 1124-1133, 1997.

29. Hasenclever D and Diehl V: A prognostic score for advanced Hodgkin's disease. International Prognostic Factors Project on Advanced Hodgkin's Disease. N Engl J Med 339: 1506-1514, 1998.

30. Vose JM, Bierman PJ, Anderson JR, Harrison KA, Dalrymple GV, Byar K, Kessinger A and Armitage JO: Single-photon emission computed tomography gallium imaging versus computed tomography: Predictive value in patients undergoing high-dose chemotherapy and autologous stem-cell transplantation for non-Hodgkin's lymphoma. J Clin Oncol 14: 2473-2479, 1996.

31. Front D, Israel $\mathrm{O}$ and Ben-Haim S: The dilema of a residual mass in treated lymphoma: The role of gallium-67 scintigraphy. In: Nuclear Medicine Annual, 1991. Freeman LM (ed). Raven Press, New York, NY, pp211-220, 1991.

32. Markova J, Kahraman D, Kobe C, Skopalova M, Mocikova H, Klaskova K, Dedeckova K, Eich HT, Böll B, Dietlein M, et al: Role of $\left.{ }^{18} \mathrm{~F}\right]$-fluoro-2-deoxy-D-glucose positron emission tomography in early and late therapy assessment of patients with advanced Hodgkin lymphoma treated with bleomycin, etoposide, adriamycin, cyclophosphamide, vincristine, procarbazine and prednisone. Leuk Lymphoma 53: 64-70, 2012.

33. Mocikova H, Pytlik R, Markova J, Steinerova K, Kral Z, Belada D, Trnkova M, Trneny M, Koza V, Mayer J, et al: Pre-transplant positron emission tomography in patients with relapsed Hodgkin lymphoma. Leuk Lymphoma 52: 1668-1674, 2011.

34. Ionescu I, Brice P, Simon D, Guermazi A, Leblanc T, Rousselot P, Gossot D, Meignin V, Gisselbrecht C and Rain JD: Restaging with gallium scan identifies chemosensitive patients and predicts survival of poor-prognosis mediastinal Hodgkin's disease patients. Med Oncol 17: 127-134, 2000.

35. Escobar IG, Barrigón DC, Tamayo P, et al: Prognostic impact of pretransplantation computed tomography and gallium scans in patients with Hodgkin lymphoma with poor prognosis undergoing hematopoietic stem cell transplantation. Clin Lymphoma Myeloma 7: 217-25, 2006

36. Hagemeister FB, Purugganan R, Podoloff DA, Hess M, Rodriguez MA, McLaughlin P, Swan F Jr, Romaguera JE and Cabanillas F: The gallium scan predicts relapse in patients with Hodgkin's disease treated with combined modality therapy. Ann Oncol 5 (Suppl 2): 59-63, 1994.

37. Delcambre C, Reman O, Henry-Amar M, Peny AM, Macro M, Cheze S, Génot JY, Tanguy A, Switsers O, Van HL, et al: Clinical relevance of gallium-67 scintigraphy in lymphoma before and after therapy. Eur J Nucl Med 27: 176-184, 2000.

38. King SC, Reiman RJ and Prosnitz LR: Prognostic importance of restaging gallium scans following induction chemotherapy for advanced Hodgkin's disease. J Clin Oncol 12: 306-311, 1994.

39. Ng AK, Bernardo MV, Silver B, Van Den Abbeele A, Stevenson MA, Fisher DC and Mauch PM: Mid- and post-ABVD gallium scanning predicts for recurrence in early-stage Hodgkin's disease. Int J Radiat Oncol Biol Phys 61: 175-184, 2005. 